\title{
Integrin a6ß4-Src-AKT signaling induces cellular senescence by counteracting apoptosis in irradiated tumor cells and tissues
}

\author{
Seung Hee Jung ${ }^{1,2} \cdot$ Minyoung Lee ${ }^{3} \cdot$ Hyun A Park ${ }^{1,2} \cdot$ Hyung Chul Lee ${ }^{1,2} \cdot$ Donghee Kang $^{1,2} \cdot$ Hyun Jung Hwang ${ }^{1,2}$. \\ Chanho Park ${ }^{2} \cdot$ Dong-Min Yu ${ }^{4} \cdot$ Yu Ri Jung ${ }^{3} \cdot$ Mi-Na Hong ${ }^{3} \cdot$ Yong-Nyun Kim ${ }^{5} \cdot$ Heon Joo Park ${ }^{2,6} \cdot$ Young-Gyu Ko ${ }^{4}$. \\ Jae-Seon Lee $\mathbb{1}^{1,2}$
}

Received: 5 September 2017 / Revised: 7 March 2018 / Accepted: 22 March 2018 / Published online: 21 May 2018

(c) ADMC Associazione Differenziamento e Morte Cellulare 2018

\begin{abstract}
Cellular senescence refers to an irreversible growth arrest that is triggered by various intrinsic and extrinsic stresses. Many recent studies have demonstrated that cellular senescence plays a crucial role in the regression of tumors exposed to ionizing radiation (IR), but the underlying mechanism remains unknown. Here we show that the activation of integrin $\beta 4$ is essential for IR-induced cellular senescence. IR treatment results in the phosphorylation of integrin $\beta 4$ at tyrosine residue 1510, leading to activation of the integrin $\alpha 6 \beta 4$-Src-AKT signaling pathway. We further reveal that the IR-induced phosphorylation of integrin $\beta 4$ is regulated by the cholesterol content and membrane fluidity. We also find that IRinduced p53-caspase signaling is independent of integrin $\alpha 6 \beta 4$-Src-AKT signaling. Finally, we show that siRNA- or inhibitor-mediated blockade of integrin $\alpha 6 \beta 4$-Src-AKT signaling switches the post-irradiation fate from senescence to apoptosis, under p53 activated condition, in both cancer cells and tumor tissues of xenograft mice. On the basis of our finding that, integrin $\alpha 6 \beta 4$ is specifically activated and acts primarily to induce premature senescence in irradiated cancer cells, we propose that this integrin may be a valuable target and biomarker for radiotherapy.
\end{abstract}

Edited by R Johnston

Electronic supplementary material The online version of this article (https://doi.org/10.1038/s41418-018-0114-7) contains supplementary material, which is available to authorized users.

Jae-Seon Lee

jaeslee@inha.ac.kr

1 Department of Molecular Medicine, Inha University College of Medicine, Incheon, Korea

2 Hypoxia-related Disease Research Center, Inha University College of Medicine, Incheon, Korea

3 Radiation Non-clinical Center, Korea Institute of Radiological and Medical Sciences, Seoul, Korea

4 Division of Life Sciences, Korea University, Seoul, Korea

5 Division of Cancer Biology, Research Institute, National Cancer Center, Goyang, Korea

6 Department of Microbiology, Inha University College of Medicine, Incheon, Korea

\section{Introduction}

Radiotherapy (RT) is a major therapeutic regimen for a wide range of malignant tumors [1]. Numerous studies have focused on effective strategies for using ionizing radiation (IR) to induce apoptosis in malignant cells. However, accumulating evidence indicates that apoptosis is not the only mechanism responsible for the IR-induced cessation of cell growth $[2,3]$. It is now recognized that the self-renewal capacity can alternatively be lost through premature senescence, and that such cells fail to undergo apoptosis in response to IR [2, 4, 5]. Indeed, recent in vitro and in vivo studies have demonstrated that cellular senescence plays a crucial role in IR-induced tumor regression $[2,3,6,7]$.

Cellular senescence is a metabolically active state of irreversible growth arrest [8]. Almost four decades since the first observation of replicative senescence, cellular senescence was demonstrated in a variety of tumor cells and tumor tissues from mice and humans [4]. Senescence is primarily triggered by DNA-damage responses (DDRs) and characterized by specific phenotypes [9-12]. Recent studies demonstrated that cellular 

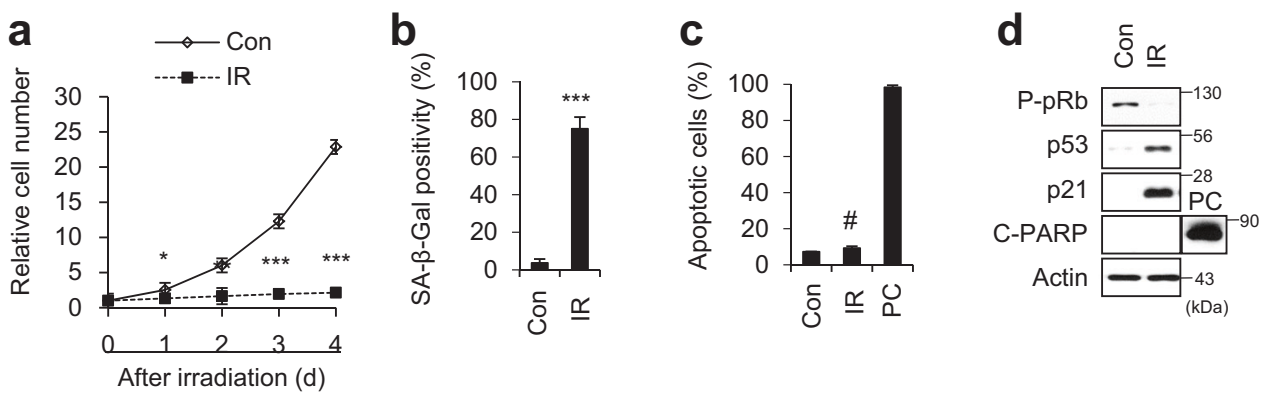

e

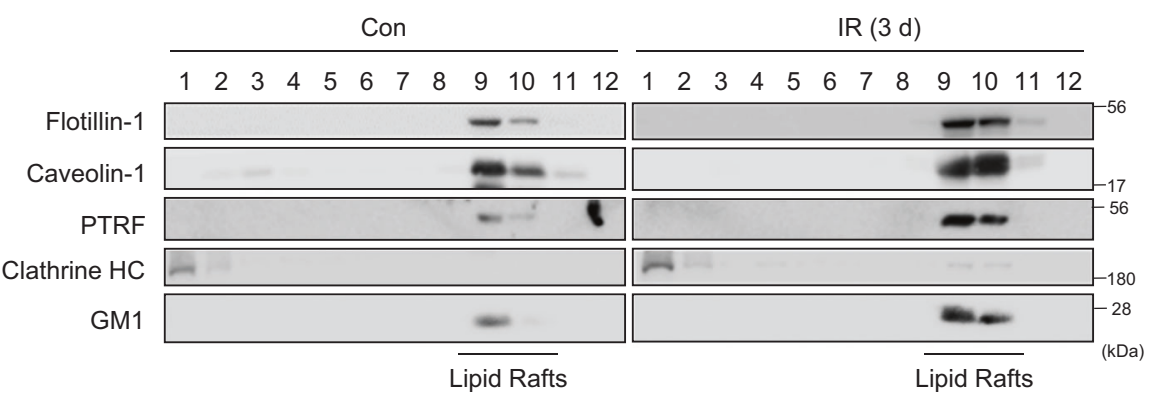

f
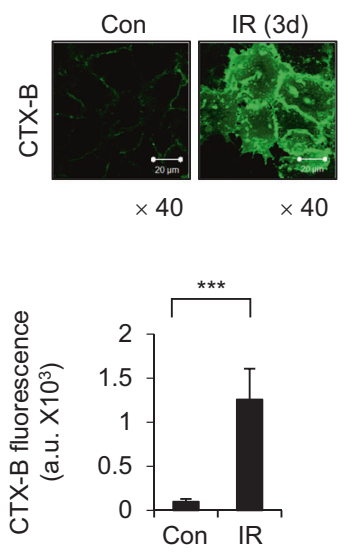

Fig. 1 Lipid rafts are increased undergoing IR-induced cellular senescence. a-d Human lung carcinoma A549 cells were irradiated with 6 Gy IR. The relative cell numbers were determined on the indicated days, with the viable cell number on day 0 after irradiation set to 1 (a). Cells were irradiated and subjected to SA- $\beta$-Gal staining (b), Annexin V staining (c), and immunoblotting (d). e A549 cells were exposed to $6 \mathrm{~Gy}$ IR, and lipid rafts were fractionated on day 3 post-IR. Equal volumes of each fraction were resolved by SDS-PAGE, and immunoblotting was performed with the indicated antibodies. Clathrin heavy chain (HC) was used as a marker for cytoplasmic fractions. f Cells exposed to 6 Gy IR were stained with CTX-B on day

senescence is also involved in embryonic development [13]. Senescence is mainly controlled through p53 and p16-pRb pathways [14]. Activation of p53 by the DDR triggers senescence-associated growth arrest, primarily by inducing the expression of $\mathrm{p} 21$, a cyclin-dependent kinase (CDK) inhibitor [15]. However, the DDR-activated p53 ironically also induces many pro-apoptotic molecules. We still do not g

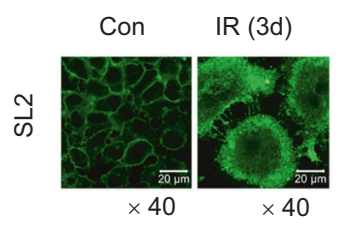

Hydrophilic Hydrophobic

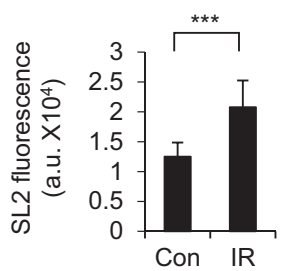

3 post-IR, and observed under confocal microscopy (upper panel). The fluorescence intensities of CTX-B per area $\left(\mathrm{mm}^{2}\right)$ were quantified from 50 different cells (lower graph). g Cells exposed to 6 Gy IR were stained with SL2 $(10 \mu \mathrm{M})$ for $10 \mathrm{~min}$ at room temperature and observed under a two-photon microscope (upper panel). The SL2 fluorescence intensities per area $\left(\mathrm{mm}^{2}\right)$ were quantified from 30 different cells (lower graph). Scale bars indicate $20 \mu \mathrm{m}$. The values represent the mean $\pm \mathrm{SD}$ of three independent experiments; $* * *, * *$ and \# indicate $p<0.001, p<0.01$, and $p>0.05$, respectively, as assessed by $t$ test

understand exactly how DDR-activated p53 induces senescence instead of apoptosis.

Lipid rafts are membrane microdomains that are enriched in glycosphingolipids and cholesterol and act as platforms for the recruitment of signaling proteins [16, 17]. The integrins, a large family of heterodimeric glycoprotein receptors are enriched in lipid rafts [18], and function 
a

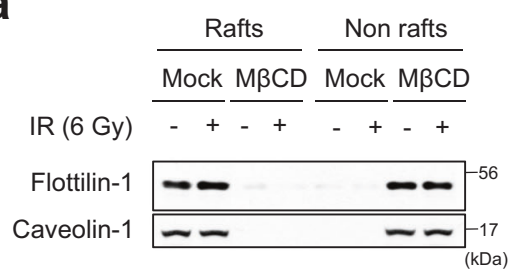

C

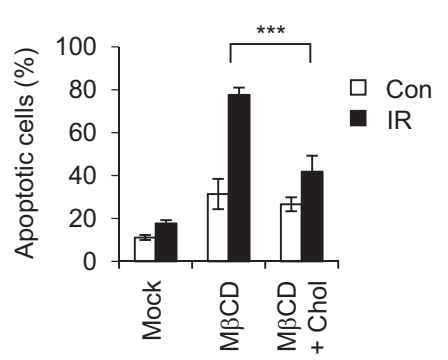

b

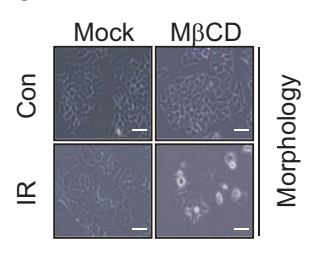

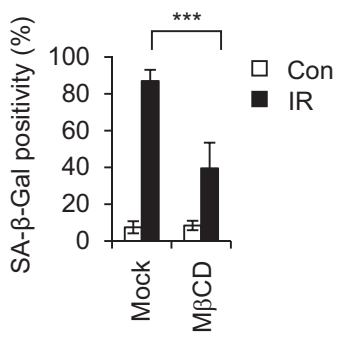

d

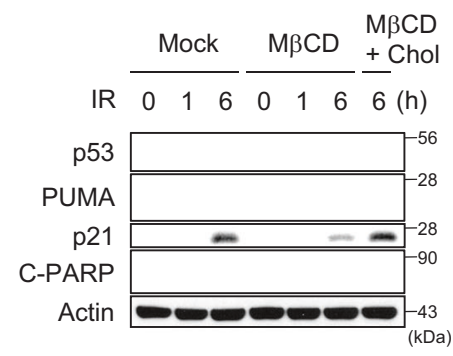

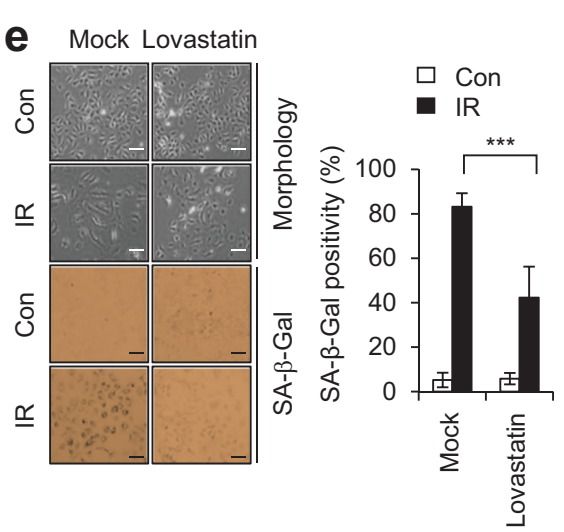

Fig. 2 Disruption of lipid rafts switches the cell fate from senescence to apoptosis in IR-exposed cells. a A549 cells pre-incubated with $0.1 \mathrm{mMM} \beta \mathrm{CD}$ were irradiated with 6 Gy IR for 3 days, and lipid rafts were fractionated. Equal volumes of lipid rafts (Rafts; fractions 8-10) and non-lipid rafts (Nonrafts; fractions 3-6) were resolved by SDS-PAGE, and immunoblotting was performed with the indicated antibodies. b Morphological changes and SA- $\beta$-Gal positivity were observed 3 days after irradiation (left panel). Senescent cells were quantified (right graph). c, d A549 cells were sequentially treated with $0.1 \mathrm{mM} \mathrm{M} \beta \mathrm{CD}$, an $\mathrm{M} \beta \mathrm{CD} /$ cholesterol mixture $(\mathrm{M} \beta \mathrm{CD}+\mathrm{Chol}$; to

as the major receptors for cell adhesion to connect the intracellular and extracellular environments [19]. Mammals express 18 different $\alpha$ and $\beta$ integrin subunits that assort into 24 unique $\alpha \beta$ heterodimers [19-21]. Integrins are increasingly being recognized as attractive therapeutic targets for various diseases, particularly cancers [22]. Indeed, lipid rafts and integrins are thought to be involved in chemo- and radio-resistance during cancer treatment $[23,24]$. However, the roles of lipid rafts and integrins in IR-induced cellular senescence are not yet known. replete cholesterol), and then IR. Annexin V-positive cells were determined 1 day after irradiation (c). Cells were lysed and immunoblotted with the indicated antibodies (d). e-g A549 cells pre-incubated with $20 \mu \mathrm{M}$ Lovastatin were irradiated with 6 Gy IR. Morphological changes and SA- $\beta$-Gal-positive cells were observed at day 4 after irradiation (left panel). Senescent cells were quantified (right graph) (e). Annexin V-positive cells were determined (f). Immunoblotting was performed $(\mathbf{g})$. Scale bars indicate $10 \mu \mathrm{m}$. The values represent the mean \pm SD of three independent experiments; $* * *$ indicates $p<0.001$, as assessed by $t$ test

Here, we provide evidence that lipid rafts are involved in the IR-induced cellular senescence of cancer cells. We show that lipid raft disruption shifts the cell fate from senescence to apoptosis in irradiated cells. We further report that IR induces dimerization of integrin $\beta 4$ with integrin $\alpha 6$ and phosphorylation of integrin $\beta 4$ at tyrosine residue 1510 in lipid rafts, which leads to the activations of Src-AKT signaling pathway. Finally, we reveal that this activated AKT blocks p21 cleavage and caspase activation, eventually leading to senescence instead of apoptosis in IR-exposed cancer cells. 


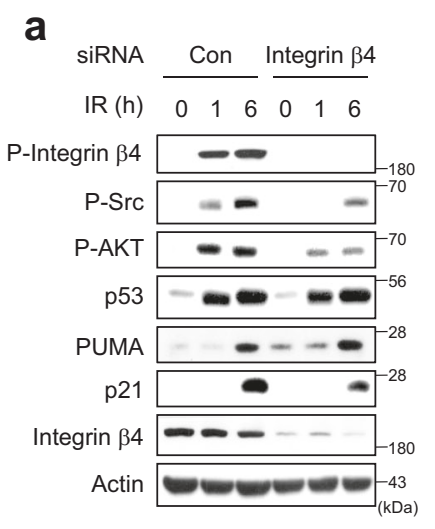

b

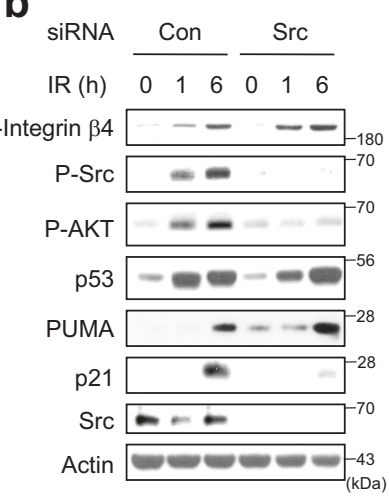

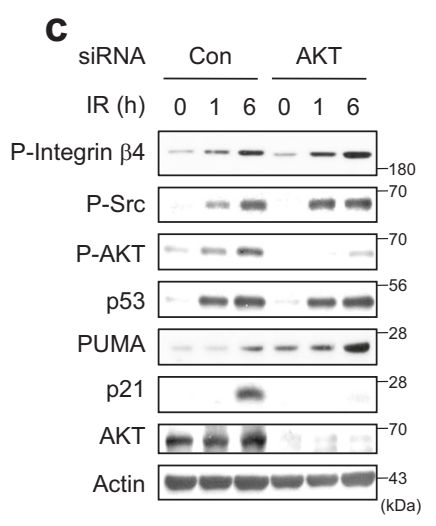

C

d
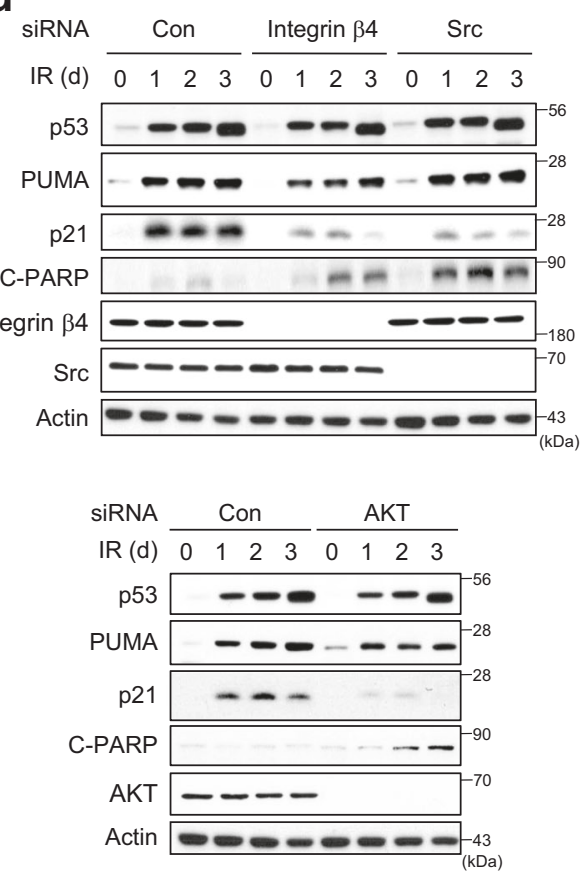

Fig. 3 The integrin $\alpha 6 \beta 4$-Src-AKT signaling pathway is essential for the IR-induced cellular senescence. a-d A549 cells were transfected with each indicated siRNA and then exposed to 6Gy IR. Immunoblotting was performed with the indicated antibodies at various time intervals after irradiation. Actin served as the loading

\section{Results}

\section{Lipid rafts are crucial for the IR-induced cellular senescence}

Consistent with our previous reports [6, 25, 26], A549 cells exposed to 6 Gy IR exhibited typical senescence phenotypes (Fig. 1a-d). To explore whether these senescent cells exhibited changes in their lipid rafts, we first obtained lipid raft fractions from IR-exposed senescent A549 cells, and examined the expression levels of the main protein components of lipid rafts, including flotillin-1, caveolin-1, and polymerase I and transcript release factor (PTRF) [16]. Western blotting revealed that the expression levels of e

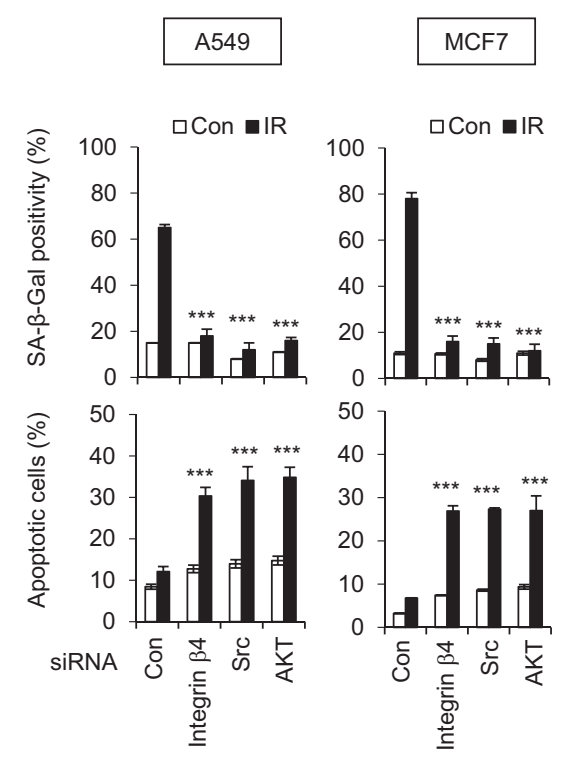

control. e Positivities of SA- $\beta-$ Gal (upper panel) and Annexin V (lower panel) were assessed in each $\mathrm{Si}$-treated/irradiated cell group. The values represent the mean $\pm \mathrm{SD}$ of three independent experiments; $* * *$ and \# indicate $p<0.001$ and $p>0.05$, respectively, as assessed by $t$ test

flotillin-1, caveolin-1, and PTRF were increased in the senescent cells compared to proliferating cells (Fig. 1e). To visualize lipid rafts on the surface of cells, we bound ganglioside GM1, with bacterial-derived cholera toxin B subunit (CTX-B) [27]. Quantification of the fluorescence intensity of GM1 per area $\left(\mathrm{mm}^{2}\right)$ revealed that this intensity was higher in senescent cells (Fig. 1f), as immunoblot analysis of GM1 (Fig. 1e). Lipid rafts are less fluid (more rigid) than phospholipid membranes, and plasma membranes with more lipid rafts might exhibit decreased fluidity [28]. Thus, we examined plasma membrane fluidity with the hydrophobic two-photon dye, S-Laurdan2 (SL2) [29]. Quantification revealed that the intensity SL2 per area $\left(\mathrm{mm}^{2}\right)$ was also increased in senescent cells 
(Fig. 1g). These results demonstrate that the proportion of lipid rafts in the plasma membrane was increased in A549 cells in which IR had induced premature senescence.

To investigate whether lipid rafts are critical for IRinduced premature senescence, we disrupted the lipid rafts by using methyl-beta-cyclodextrin (M $\beta C D)$. M $\beta C D$ treatment shifted the partitioning of flotillin-1 and caveolin-1 from lipid rafts to non-lipid raft fractions in both control and IR treated cells (Fig. 2a). We found cells treated with $\mathrm{M} \beta \mathrm{CD}$ followed by IR exposure underwent apoptosis instead of senescence (Fig. 2b-d). Exposure to IR was associated with less positivity for SA- $\beta$-Gal (a senescence marker) and more positivity for Annexin V (an apoptosis marker) in $\mathrm{M} \beta \mathrm{CD}$-treated cells compared to IR-alone cells (Fig. 2b,c). IR exposure had no effect on p53 activation or PUMA induction, but dramatically decreased p21 induction and increased PARP cleavage in M $\beta C D$-treated cells (Fig. 2d). Furthermore, repletion of cholesterol using a $\mathrm{M} \beta \mathrm{CD} / \mathrm{Cholesterol} \mathrm{mixture}(\mathrm{M} \beta \mathrm{CD}+\mathrm{Chol})$ restored the p21 induction and reduced PARP cleavage compared to those seen in M $\beta C D$-treated cells after irradiation (Fig. 2d). The apoptotic cell population was lower in the cholesterolreplete cells compared to non-replete cells treated with M $\beta C D$ and IR (Fig. 2c). Additionally, when cholesterol was depleted using Lovastatin [30], IR exposure induced apoptosis instead of cellular senescence in A549 cells (Fig. 2e-g). In 6 Gy IR-exposed MCF7 cells exhibited typical senescence phenotypes (Supplementary Figure S1ad), M $\beta C D$ treatment also shifted the cell fate from senescence to apoptosis, and cholesterol repletion blocked this M $\beta C D$-mediated apoptosis (Supplementary Figure S1e and f). These data suggest that lipid rafts are critical for the ability of 6 Gy IR to induce premature senescence in A549 and MCF7 cancer cells.

\section{Integrin $\beta 4$-Src-AKT signaling is critical for the IR- induced cellular senescence}

To identify molecules involved in the IR-induced cellular senescence, we performed a phospho-antibody array analysis. Ingenuity Pathway Analysis (IPA) revealed that 433 phosphoproteins showed altered expression in IR-induced senescent MCF7 cells (Supplementary Figure S2a). The phosphorylation statuses of integrin $\beta 4$, Src, and AKT, which all participate in the same signaling pathway, were altered in IR-induced senescent cells (Supplementary Figure S2b): following 6 Gy IR of A549, MCF7, and H460 cells, integrin $\beta 4, \mathrm{Src}$, and $\mathrm{AKT} 1 / 2$ were phosphorylated (Supplementary Figure S2c).

Next, we employed siRNA ( $\mathrm{Si}$ ) against integrin $\beta 4$, Src, or AKT to establish the roles of these molecules in the IRinduced cellular senescence. We found that integrin $\beta 4$ depletion diminished the phosphorylations of Src and AKT in 6 Gy IR-exposed cells (Fig. 3a). However, the depletion of Src or AKT had no effect on the phosphorylation status of integrin $\beta 4$ (Fig. 3b, c). AKT phosphorylation was abolished in Src-depleted cells, but Src phosphorylation was unchanged in AKT-depleted cells (Fig. 3c). These results indicate that $6 \mathrm{~Gy}$ IR activates the integrin $\beta 4-S r c-A K T$ signaling cascade. In integrin $\beta 4 \mathrm{Si}$-, Src Si-, or AKT Si-treated cells, p21 accumulation was dramatically diminished, but the accumulations of p53 and PUMA were not affected (Fig. $3 \mathrm{a}-\mathrm{c}$ ). These changes were consistent in all Si-transfected cells, even in longer incubation durations (1, 2, and 3 days) (Fig. 3d). The accumulation of p21 was inversely correlated with PARP cleavage (C-PARP), regardless of p53 activation or PUMA induction (Fig. 3d). Integrin $\beta 4 \mathrm{Si}, \mathrm{Src} \mathrm{Si}$, or AKT Si treatment was associated with decreased SA- $\beta$-Gal positivity and increased Annexin V positivity in both A549 and MCF7 cells (Fig. 3e). No off-target effect of integrin $\beta 4$ was confirmed by the treatment other siRNAs against integrin $\beta 4$ (Supplementary Figure S3). Next, we examined cellular response to IR exposure in p53 mutant MDA-MB231 cells. The proportion of SA- $\beta$-Gal-positive MDA-MB231 cells was much lower than that of p53 wild-type A549 and MCF7 cells following IR exposure (Supplementary Figure $\mathrm{S} 4 \mathrm{a}-\mathrm{d}$ ). Cell fate was not shifted from senescence to apoptosis in the absence of integrin $\beta 4$ in MDA-MB231 cells by IR exposure (Supplementary Figure S4e-g). When non-transformed human diploid fibroblast (HDF) cells were exposed to IR, we found that $\sim 40 \%$ of the cells were SA- $\beta$ Gal positive and cell fate was shifted from senescence to apoptosis in the absence of integrin $\beta 4$ (Supplementary Figure S5). These results indicate that p21 could be induced by the p53-independent mechanism as previously described [31], ultimately inducing cellular senescence. However, p53 is indispensable to shift cell fate from senescence toward apoptosis.

To examine whether other integrin family members were also involved in IR-induced cellular senescence, we depleted A549 cells of integrin $\beta 1,-3$, or -5 , which are commonly expressed in mammalian cells [19], and then performed IR exposure. Depletion of integrin $\beta 1$ or integrin $\beta 3$ rather slightly increased the SA- $\beta-G a l$ positivity, but had no effect on apoptosis among irradiated cells (Supplementary Figure S6a-c). Depletion of integrin $\beta 5$ did not affect the SA- $\beta$-Gal positivity, but significantly increased apoptosis among irradiated cells (Supplementary Figure $\mathrm{S} 6 \mathrm{a}-\mathrm{c})$. The siRNA-mediated knockdowns of integrin $\beta 1,-3,-4$, and -5 were confirmed by qRT-PCR analysis (Supplementary Figure S6d). Together, our results suggest that integrin $\beta 4$ is specifically involved in the IR-induced cellular senescence of cancer cells. 
a
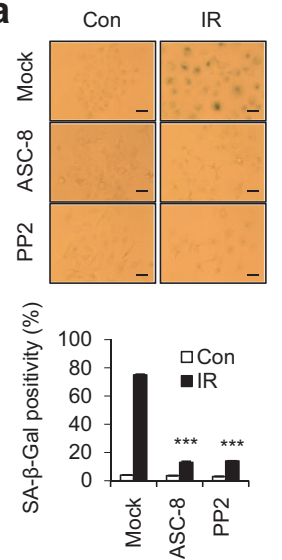

d

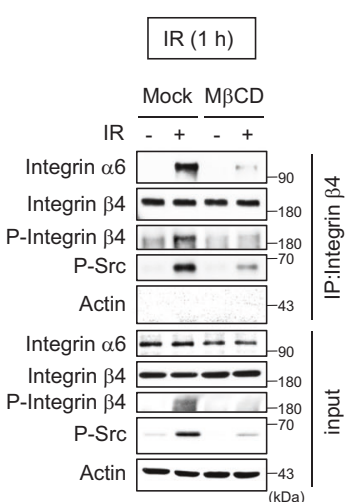

f

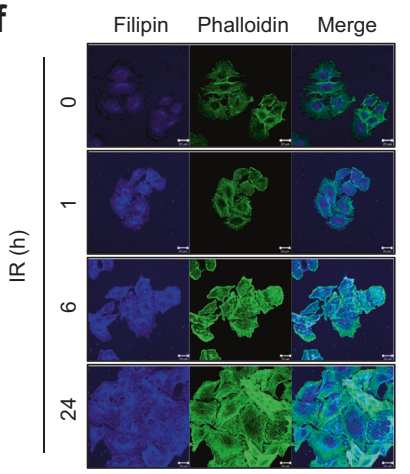

h

$\frac{\text { Mock }}{\mathrm{IR}} \frac{\text { Oleic Acid }}{\mathrm{IR}}$

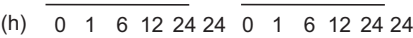

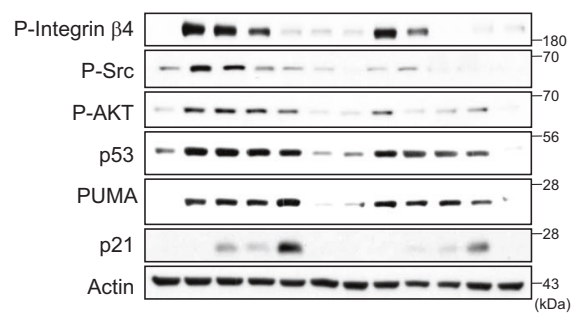

e

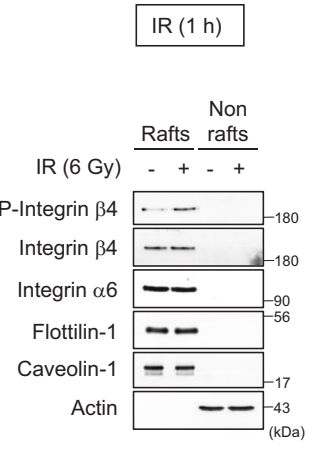

C

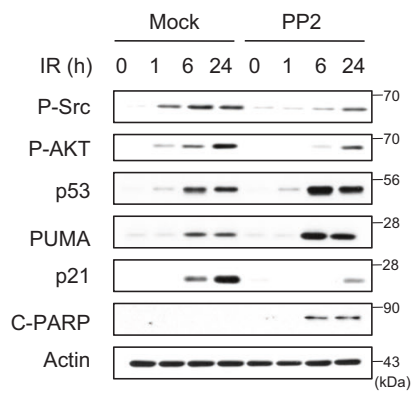


Fig. 4 Integrin $\beta 4$ and $\alpha 6$ dimerize during the IR-induced cellular senescence. a-c A549 cells pre-incubated with an inhibitor of integrin $\beta 4$ (ASC-8) or Src (PP2) were irradiated with 6 Gy IR. SA- $\beta-G a l$ positivity was observed 3 days after irradiation. Scale bars indicate 10 $\mu \mathrm{m}$ (a). Immunoblotting was performed with the indicated antibodies at various time intervals after irradiation. Actin served as the loading control $(\mathbf{b}, \mathbf{c})$. d A549 cells pre-incubated with $0.5 \mathrm{mM} \mathrm{M} \beta C D$ were irradiated with 6 Gy IR. At $1 \mathrm{~h}$ post-irradiation, immunoprecipitates were prepared with anti- $\alpha$-integrin $\beta 4$, and then immunoblotted with anti- $\alpha$-integrin $\alpha 6$. e A549 cells were irradiated with 6 Gy and incubated for $1 \mathrm{~h}$, and lipid rafts were fractionated. Equal volumes of lipid rafts (Rafts; fractions 8-10) and nonlipid rafts (Nonrafts; fractions 3-6) were resolved by SDS-PAGE, and immunoblotting was performed with the indicated antibodies. Actin was used as a marker of nonraft fractions. f A549 cells were irradiated with $6 \mathrm{~Gy}$, incubated for the indicated times, and then labeled with filipin and Alexa Fluor 488 phalloidin. The fluorescence intensities of filipin per area $\left(\mathrm{mm}^{2}\right)$ were quantified from 15 different cells using the ImageJ program. Scale bars indicate $20 \mu \mathrm{m}$. g A549 cells were irradiated with 6 Gy and incubated for the indicated times, and the cholesterol contents in cells were measured using an Amplex Red cholesterol assay kit. The results are expressed with respect to the amount of protein. h, i A549 cells preincubated with oleic acid were irradiated with 6 Gy IR. Cell lysates prepared at the indicated time intervals were immunoblotted (h), and SA- $\beta$-Gal staining (i) was performed. Scale bars indicate $10 \mu \mathrm{m}$. The values represent the mean $\pm \mathrm{SD}$ of three independent experiments; $* * *$ indicates $p<0.001$, as assessed by $t$ test

\section{Integrin $\beta 4$ and $a 6$ dimerize during the IR-induced cellular senescence}

When we inhibited the activities of integrin $\beta 4$ with ASC-8 or Src with PP2, the IR-induced premature senescence was clearly diminished (Fig. 4a). Under these circumstances, p21 accumulation was decreased and PARP cleavage was increased (Fig. 4b, c). However, blocking the activation of integrin $\beta 4$ or Src did not affect p53 accumulation or PUMA induction (Fig. $4 \mathrm{~b}, \mathrm{c}$ ). As the integrin $\beta 4$ subunit associates exclusively with the $\alpha 6$ subunit to form the $\alpha 6 \beta 4$ heterodimer [32], we used co-immunoprecipitation (IP) to examine whether such dimerization was associated with the IRinduced cellular senescence. At $1 \mathrm{~h}$ after IR exposure, we saw dramatic increases in the dimerization of these two integrin subunits and the phosphorylation of integrin $\beta 4$, but no change in the expression levels of integrin $\alpha 6$ of integrin $\beta 4$ (Fig. 4d). The phosphorylated Src was recruited to the integrin $\alpha 6 \beta 4$ dimers (Fig. 4d). The phosphorylation of integrin $\beta 4$ and its heterodimerization with integrin $\alpha 6$ were both abolished (Fig. 4d), and enhanced levels of phosphorylated integrin $\beta 4$ were observed in the lipid rafts at $1 \mathrm{~h}$ post-irradiation by M $\beta C D$ treatment (Fig. 4e). These data indicate that lipid rafts are critical for the IR-induced phosphorylation of integrin $\beta 4$.

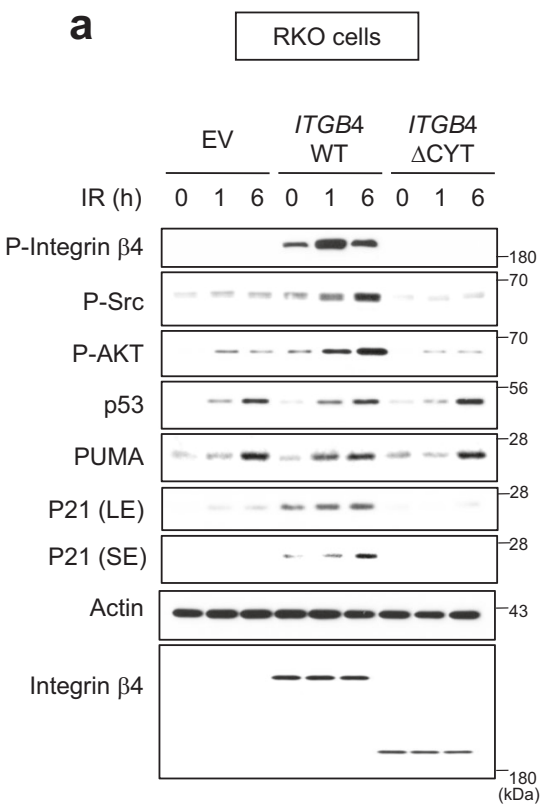

Fig. 5 The phosphorylation domain of integrin $\beta 4$ critically contributes to switching the fate of IR-exposed cells from apoptosis to senescence. RKO colon cancer cells were transfected with empty vector (EV) or gene encoding wild-type ITGB4 (WT) or a truncated mutant of ITGB4 lacking the residues downstream of amino acid $1355(\triangle \mathrm{CYT})$, and then exposed to 6 Gy IR. a Cell lysates were prepared at the indicated time points after irradiation, and subjected to immunoblotting. LE and b

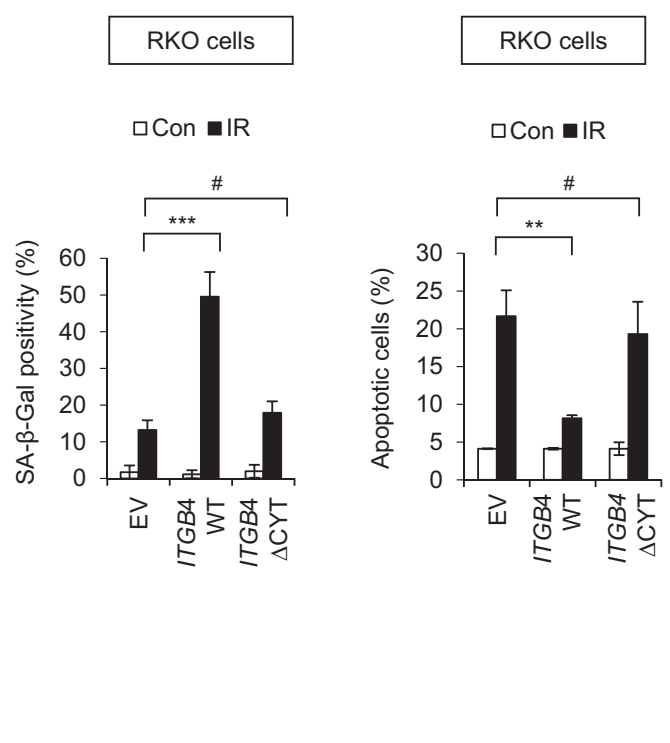

SE indicate long and short exposure, respectively. b SA- $\beta$-Gal-positive cells were examined (left) and quantified (right) at 3 days after IR exposure. c Annexin V positivity was assessed 1 day after irradiation. The values represent the mean \pm SD of three independent experiments; ** and \# indicate $p<0.01$ and $p>0.05$, respectively, as assessed by $t$ test 
Fig. 6 Blockade of caspase activation compensates for the roles of integrin $\beta 4$ and AKT in the IR-induced cellular senescence. a-f A549 cells were transfected with $(\mathbf{a}-\mathbf{c})$ integrin $\beta 4 \mathrm{Si}$ or $(\mathbf{d}-\mathbf{f}) \mathrm{AKT} \mathrm{Si}$, and subsequently treated with $20 \mu \mathrm{M}$ Z-VAD-FMK (a pan-caspase inhibitor). Cells were exposed to 6 Gy IR and cell lysates were prepared for immunoblotting. Actin served as the loading control (a, d). SA- $\beta$-Gal positivity was determined 3 days after irradiation. Scale bars indicate $10 \mu \mathrm{m}(\mathbf{b}, \mathbf{e})$. Quantification of Annexin Vpositive cells was performed 1 day after irradiation $(\mathbf{c}, \mathbf{f})$. The values represent the mean $\pm S D$ of three independent experiments; *** indicates $p<$ 0.001 , as assessed by $t$ test a

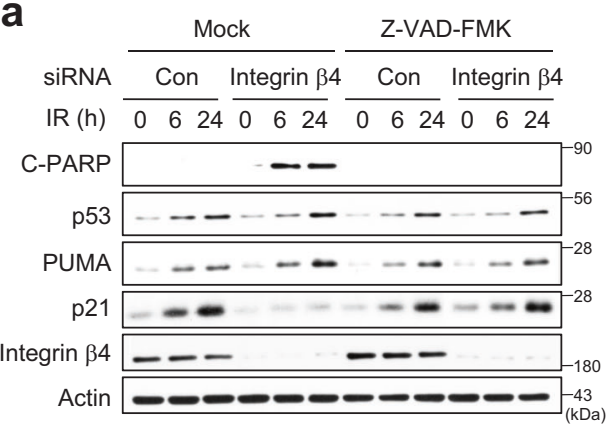

b

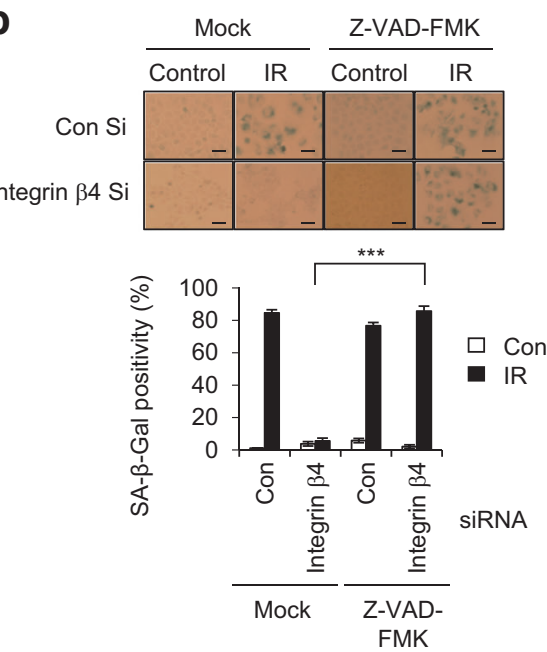

C

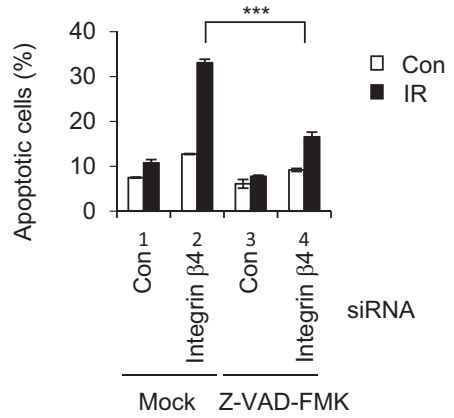

d

\begin{tabular}{|c|c|c|c|c|}
\hline \multirow[b]{2}{*}{ siRNA } & \multicolumn{2}{|c|}{ Mock } & \multicolumn{2}{|c|}{ Z-VAD-FMK } \\
\hline & Con & AKT & Con & AKT \\
\hline & 62 & 624 & $\begin{array}{lll}0 & 624\end{array}$ & 0624 \\
\hline
\end{tabular}

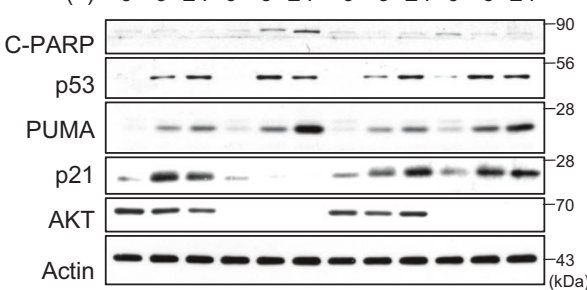

e
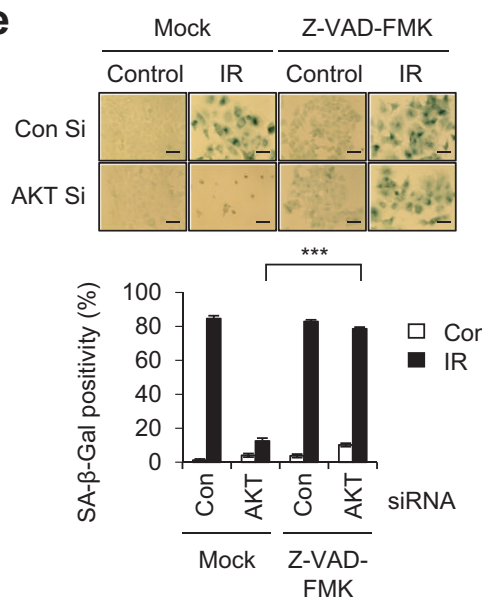

f

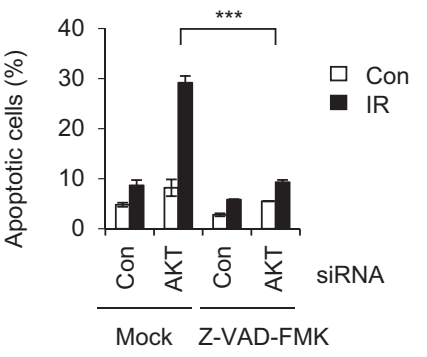

Filipin is an antibiotic polyene used as a histochemical cholesterol marker [33]. The proportion of filipin-stained cells gradually and time-dependently increased following irradiation (Fig. 4f), indicating that irradiation triggered a sustained increase in cholesterol level. We observed a similar increase of the cholesterol content in irradiated cells using Amplex red (Fig. 4g). Next, we examined the effect of a membrane fluidizer (oleic acid) [34] on the activation of the integrin $\alpha 6 \beta 4$-Src-AKT signaling cascade in irradiated cells. We found that oleic acid-treated cells exposed to IR exhibited decreases in integrin $\beta 4$-Src-AKT activation and p21 induction, but no evident change in the levels of p53 or PUMA (Fig. 4h). The proportion of senescent cells was decreased in IR-exposed oleic acid-treated cells (Fig. 4i). These results support that integrin $\alpha 6 \beta 4$-Src-AKT signaling is dependent on the cholesterol content and membrane fluidity during IR-induced senescence.

To define the role of integrin $\beta 4$ in IR-induced cellular senescence, we transfected RKO cells having no endogenous integrin $\beta 4$ expression [35] with vectors encoding integrin $\beta 4$ wild-type gene (ITGB4 WT) or the integrin $\beta 4$ $\triangle C Y T$ mutant gene (ITGB4 $\triangle \mathrm{CYT}$ ) lacking the tyrosine phosphorylation site-containing cytoplasmic tail [36]. The expression of ITGB4 WT increased the phosphorylations of integrin $\beta 4$, Src, and AKT, and the expression of p21, as compared to those in IR-exposed RKO cells transfected with empty vector (EV) (Fig. 5a). In contrast, ITGB4 $\triangle$ CYT-transfected cells exposed to IR showed no activation of integrin $\beta 4$-Src-AKT signaling or induction of p21 (Fig. 5a). Meanwhile, p53 accumulation and PUMA 
Fig. 7 Integrin $\alpha 6 \beta 4-S r c-A K T$ signaling is critical for IRinduced cellular senescence in the tumor tissues of xenograft mice. $\mathrm{H} 460$ cells $\left(1 \times 10^{6}\right)$ were injected subcutaneously into female nude mice. When the tumor volume reached $100 \mathrm{~mm}^{3}$, $200 \mu \mathrm{l}$ AteloGene gel containing integrin $\beta 4 \mathrm{Si}$ or PP2 (a Src inhibitor) was injected to encompass the whole tumor mass. After 1 day, 12 Gy radiation was applied. a The tumor size $\left(\mathrm{mm}^{3}\right)$ was measured at the indicated times. Error bars represent $\pm \operatorname{SEM}(n=5)$. b, c H\&E staining, TUNEL, Ki-67 immunostaining, and p21 immunostaining were performed on tumor sections derived from xenograft mice exposed to IR (b), and the Ki-67-, p21-, and TUNEL-positive cells per field were quantified (c). Scale bars indicate $10 \mu \mathrm{m}$. Arrows indicate apoptotic cells. d Tumor lysates obtained at 8 days after irradiation were subjected to immunoblot analysis. e Pictures of SA- $\beta$-Gal-stained tumors 8 days after irradiation (f-j). f Possible role of the ITG $\alpha 6 \beta 4$ Src-AKT signaling pathway in the IR-induced premature senescence. $\mathbf{k}$ Possible role of the ITG $\alpha 6 \beta 4-$ Src-AKT signaling pathway in the IR-induced premature senescence a

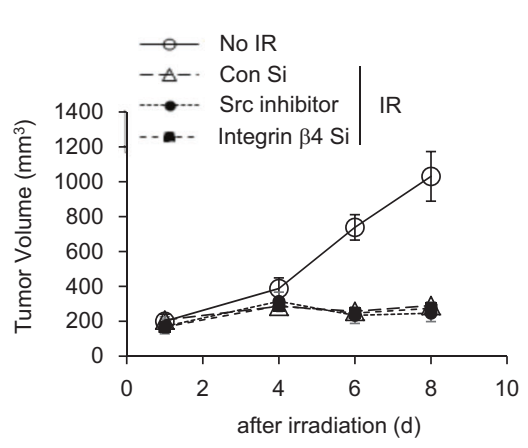

b

IR

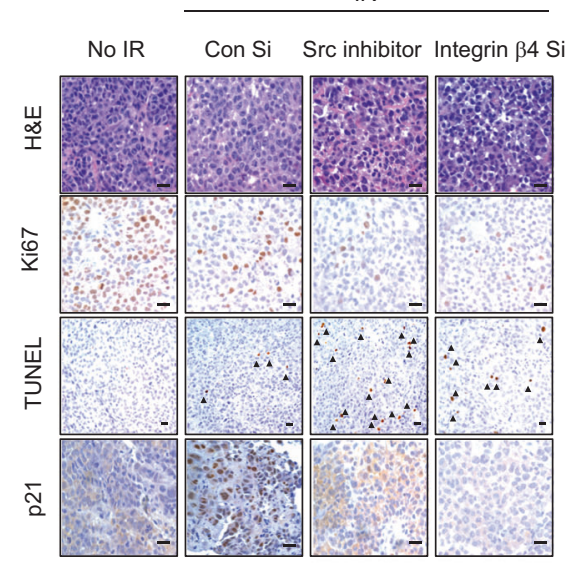

C
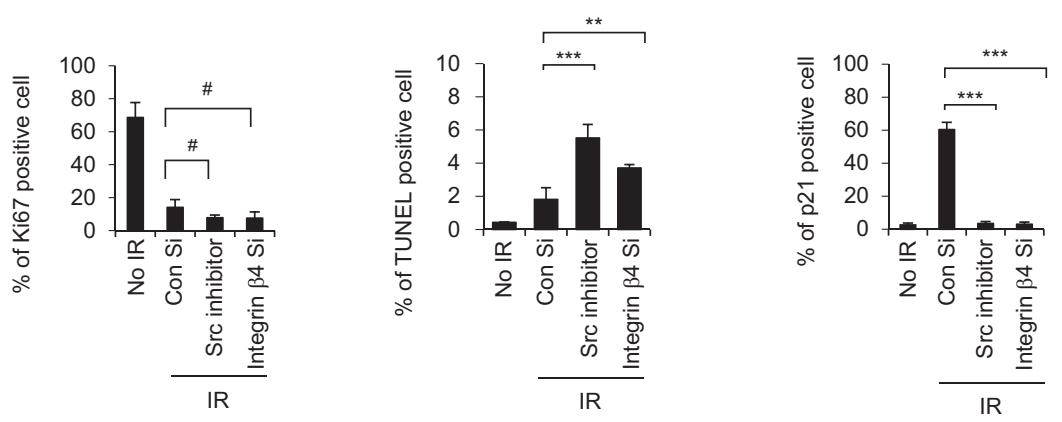

d
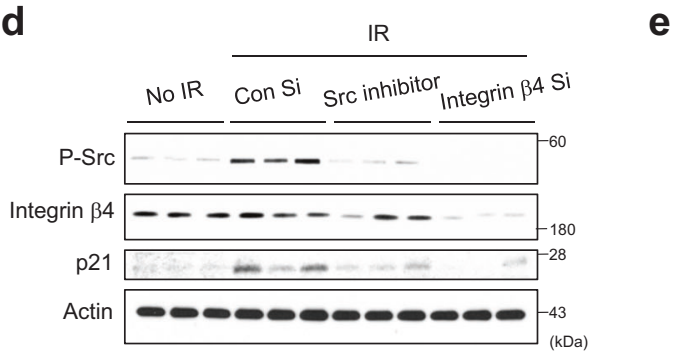

e

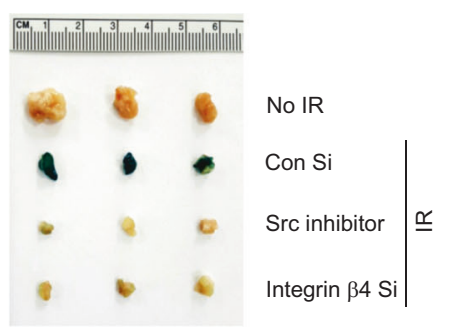

f

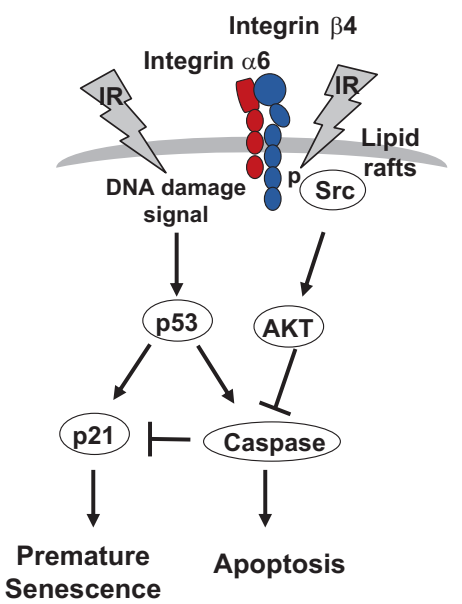

induction were consistently observed in IR-exposed EV-, ITGB4 WT-, and ITGB4 $\triangle$ CYT-transfected cells (Fig. 5a). The overexpression of ITGB4 WT triggered cellular senescence and decreased apoptosis, whereas the overexpression of ITGB4 $\triangle \mathrm{CYT}$ did not significantly affect either of these parameters (Fig. 5b, c). EV-transfected RKO 
cells showed faint signals of phospho-Src/phospho-AKT and exhibited SA- $\beta$-Gal positivity in a small proportion of cells after IR exposure (Fig. 5a). IR exposure induces ROS generation and ROS activates Src/AKT [37, 38]. To determine if IR-induced ROS was involved in Src/AKT phosphorylation and senescence induction in the absence of integrin $\beta 4$, we treated cells with NAC, a ROS scavenger, prior to irradiation of RKO cells (Supplementary Figure S7). We found that faint signals of phospho-Src/phospho-AKT disappeared and SA- $\beta$-Gal positivity decreased to control level in response to pretreatment of IR-exposed RKO cells with NAC, suggesting that IR-induced ROS contributes to Src/AKT activations and senescence phenotype to a small extent. Collectively, our data demonstrate that the phosphorylation of integrin $\beta 4$ and its dimerization with integrin $\alpha 6$ in lipid rafts primarily involves in IRinduced senescence of cancer cells via activation of the SrcAKT-p21 signaling pathway, and is critical to prevent IRinduced apoptosis pathway.

\section{The ability of integrin a6 $\beta 4-S r c-A K T$ signaling to block caspase activation is indispensable for the IR- induced cellular senescence}

In IR-exposed cancer cells, blockade of integrin $\alpha 6 \beta 4-S r c-$ AKT signaling resulted in the disappearance of p21 (targeted by p53) and the appearance of C-PARP (Figs. 3 and 4). However, such blockade did not prevent p53 accumulation or PUMA (also targeted by p53) expression, and these factors can tip the balance toward apoptosis instead of cellular senescence. p21 is rapidly induced by p53 in response to DNA damage, and is selectively cleaved by caspase activation in apoptotic cells $[39,40]$. We therefore examined whether inhibition of caspase activation could redirect the cell fate from apoptosis to senescence in IRexposed cells depleted of integrin $\beta 4$ or AKT. Indeed, treatment with Z-VAD-FMK (a pan-caspase inhibitor) rescued p21 accumulation in IR-exposed cells depleted of integrin $\beta 4$ or AKT (Fig. 6a, d), and redirected such cells from apoptosis to senescence (Fig. 6b, c, e, and f). These data demonstrate that the integrin $\alpha 6 \beta 4-$ Src-AKT signaling pathway critically contributes to the IR-induced cellular senescence by preventing the activation of caspases.

\section{Integrin $\alpha 6 \beta 4-S r c-A K T$ signaling is also required for IR-induced cellular senescence in the tumor tissues of xenograft mice}

To explore the biological significance of our findings in vivo, we examined integrin $\alpha 6 \beta 4$-Src-AKT signaling in xenograft mice. Since we previously showed that 12 Gy IR exposure effectively induces premature senescence in xenograft mice [5], we treated xenograft mice with integrin $\beta 4 \mathrm{Si}$ or the Src inhibitor, PP2, and exposed the mice to 12 Gy IR (Fig. 7). The tumor volumes of mice treated with integrin $\beta 4 \mathrm{Si}$ or PP2 in combination with IR were similar to those in mice exposed to IR alone (Fig. 7a). We performed $\mathrm{Ki}-67$ immunostaining to evaluate cell proliferation, and observed that the Ki-67-positive cell population was decreased in the IR-alone exposed group relative to nonirradiated control group, but no further decrease was evident in mice treated with integrin $\beta 4 \mathrm{Si}$ or PP2 prior to IR (Fig. 7b, c). TUNEL-positive apoptotic cells were more evident in the tumors of mice treated with integrin $\beta 4 \mathrm{Si}$ or PP2 prior to IR, compared to the IR-alone group (Fig. 7b, c). To evaluate senescent cells, we assessed p21-positive cells and p21 protein levels in tumor tissues. Both values were markedly higher in the IR-alone group compared to the groups that were treated with integrin $\beta 4 \mathrm{Si}$ or PP2 prior to IR (Fig. $7 b-d$ ). Moreover, SA- $\beta$-Gal positivity was apparent only in the tumor tissues of IR-alone mice (Fig. 7e). These findings confirmed that integrin $\alpha 6 \beta 4-$ SrcAKT signaling is critical for the ability of IR to induce the cellular senescence of cancer cells in an in vivo mouse model. On the basis of our findings, we conclude that IRtriggered integrin $\alpha 6 \beta 4-$ Src-AKT signaling counteracts the p53-caspase signaling pathway that is also activated by IR exposure, guiding the cell fate to senescence in irradiated tumor cells and tissues (Fig. 7f). Therefore, integrin $\beta 4$ could be a valuable target for radiotherapy as well as PI3K/ AKT.

\section{Discussion}

Exposure to IR triggers intracellular signaling cascades that overlap with the pathways that are initiated by receptorligand interactions. Several studies have found that membrane receptors are involved in the responses of tumor cells to IR [41, 42]. Various kinases, including protein kinase $\mathrm{C}$ (PKC), AKT, and Raf-1, were previously shown to be activated by IR treatment [43, 44]. However, the receptor signaling pathway responsible for IR-induced cellular senescence remained unknown. We speculated that radiation-induced cascades emanating in the plasma membrane could be involved in activating cytoplasmic molecules to induce cellular senescence. We herein show that IR-induced integrin $\alpha 6 \beta 4$ heterodimerization and integrin $\beta 4$ phosphorylation require an IR-induced alteration of membrane fluidity, and that integrin $\alpha 6 \beta 4$-Src-AKT signaling is critical for the IR-induced cellular senescence. We show that IR also activates the p53-caspase signaling pathway in an integrin $\alpha 6 \beta 4-$ Src-AKT signalingindependent manner. In irradiated cells, DNA-damage signaling activates p53; this rapidly induces p21, but p21 may be selectively cleaved by caspase activity under apoptotic 
conditions [39, 40]. Previously, inhibition of caspase activity was shown to switch doxorubicin-induced apoptosis to senescence [45], and AKT was shown to prevent apoptosis by inhibiting the pro-apoptotic mediator, caspase9 [46]. Here we reveal that IR activates AKT through the integrin $\alpha 6 \beta 4$-Src-AKT signaling cascade, and that this inhibits caspase activity and tips the balance toward cellular senescence instead of apoptosis. Activated p53 governs a wide variety of cell responses such as cell cycle arrest, senescence, apoptosis. Genomic instability fueled by p53 loss drives additional events to accelerate transformation, metastasis, and drug resistance [47]. However, the underlying mechanism by which p53 induces different biological responses remains unclear. One proposed mechanism is qualitative modulation of $\mathrm{p} 53$ activity via post-translational modification that can alter p53 affinity for different target genes [47]. Our data show the importance of integrin $\alpha 6 \beta 4-$ Src-AKT signaling cascade as much as pan-caspase inhibitor in IR-induced cellular senescence (Fig. 6). We observed numerous senescent cells in the tumor tissues of IR only-exposed mice, whereas the proportions of apoptotic cells were clearly increased in the tumor tissues of mice treated with integrin $\beta 4 \mathrm{Si}$ or a Src inhibitor prior to irradiation (Fig. 7). Together, our findings show for the first time that the integrin $\alpha 6 \beta 4$-Src-AKT signaling cascade is critical for the IR-induced cellular senescence of cancer cells in vitro and in vivo.

The cholesterol content is known to alter membrane fluidity [48], which in turn affects the mobility of membrane proteins $[49,50]$. We observed a rapid increase of the cholesterol content and decrease of membrane fluidity in irradiated cancer cells (Figs. 1 and 4). We also found that integrin $\beta 4$ was phosphorylated at tyrosine residue 1510 in irradiated cells (Figs. 3 and 4). In addition, the dimerization of integrin $\alpha 6$ and $\beta 4$ was dramatically increased by IR exposure, in the absence of any change in their protein expression levels (Fig. 4). Collectively, our findings suggest that IR exposure alters membrane fluidity by increasing the cholesterol content, while also contributing to integrin $\alpha 6 \beta 4$ dimerization and integrin $\beta 4$ phosphorylation. Sun et al. recently reported that integrin $\alpha 5$ activity is regulated by membrane fluidity and cholesterol content in vascular endothelial cells under oscillatory shear stress [50]. Here we demonstrate that the membrane receptor, integrin $\alpha 6 \beta 4$, is the most upstream essential molecule in IR-induced cellular senescence, and that it blocks the simultaneously activated apoptotic pathway in IR-exposed cells.

The cytoplasmic tails of the integrin $\beta$ subunits are critical for the activations of these integrins [51]. Six of the $\beta$ integrin tails (those of $\beta 1, \beta 2, \beta 3, \beta 5, \beta 6$, and $\beta 7$ ) share a high level of sequence homology [22]; they contain two NPXY or NPXY-like motifs that bind to phosphotyrosinebinding (PTB) domains in a conserved binding pocket
[22, 51]. Eke et al. [52] demonstrated that selective pharmacological targeting of integrin $\beta 1$ helped overcome the resistance of tumor cells to radiotherapy. Ramirez et al. [53] suggested that integrin $\alpha 2$ expression could be a potential biomarker for cancer diagnosis and prognosis. Rapisarda et al. [54] found integrin $\beta 3$ as a potential therapeutic target during early carcinogenesis and aging. Integrin $\beta 4$ is large, and its tail bears no homology to the short tails of the other integrin $\beta$ subunits [55]. Phosphorylation of integrin $\beta 4$ is required for signaling downstream of ERK to promote either cell survival or apoptosis [56, 57], and for signaling pathways involved in tumor growth and invasion [35]. integrin $\beta 4$ is upregulated in various tumor types [32], and enhances the signaling functions of multiple oncogenic receptor tyrosine kinases (RTKs) [20]. In addition, integrin $\beta 4$ mediates an adhesion-independent tumor-suppressive effect [58]. integrin $\alpha 6 \beta 4$ is unique among the 24 known mammalian integrins, in that it has distinctive cytoskeletal and signaling functions. As based on observations of our and other groups, we propose that integrin $\beta 4$ having unique functions could be an attractive target for cancer therapy, in particular for radiotherapy $[52,59]$.

\section{Materials and Methods}

\section{Cell lines and reagents}

MCF7, RKO, H460 and A549 cells were obtained from the American Type Culture Collection (ATCC) (Manassas, USA), and cultured in DMEM or RPMI 1640 medium (WelGENE, Daegu, Korea) containing 10\% FBS (Lonza, Basel, Switzerland) and $1 \%$ penicillin-streptomycin solution (WelGENE) at $37^{\circ} \mathrm{C}$ under $5 \% \mathrm{CO}_{2}$. The cell lines were certified by short tandem repeat analysis. Cells were exposed to a ${ }^{137} \mathrm{Cs} \gamma$-ray source (Atomic Energy of Canada Ltd., Chalk River, Ontario, Canada) at a dose rate of $3.2 \mathrm{~Gy} /$ $\mathrm{min}$. Other materials used were procured from the following sources: methyl- $\beta$-cyclodextrin $(\mathrm{M} \beta \mathrm{CD})$, cholesterol, and oleic acid (Sigma, St. Louis, MO, USA); anti- integrin $\beta 4$ antibody and clone ASC-8 for blocking integrin $\beta 4$ activity (Merck Millipore, Billerica, MA, USA); Lovastatin and PP2 (Merck Millipore, Billerica, MA, USA); Z-VAD-FMK (R\&D Systems, Minneapolis, MN, USA).

\section{Immunoblotting}

For western blot analysis (WB), cell lysates were prepared in RIPA lysis buffer containing protease inhibitors (Roche, Basel, Switzerland) and phosphatase inhibitors (Sigma). Lysates were mixed with $2 \times$ Laemmli sample buffer, boiled, and subjected to sodium dodecyl sulfate polyacrylamide gel 
electrophoresis (SDS-PAGE). After transferring proteins to a nitrocellulose membrane, WB was performed by blocking the membrane with 5\% non-fat dried milk, and incubating with various primary antibodies (Abs), followed by horseradish peroxidase-conjugated secondary Abs. WB detection was conducted with ECL reagents (Thermo Fisher Scientific, Waltham, MA, USA). Primary antibodies included phospho-AKT at S473 (P-AKT), phospho-Src at Y416 (PSrc), AKT, Src, FAK, cleaved PARP (C-PARP), and PUMA (Cell Signaling Technology, Danvers, MA, USA); Flotillin-1 and p21 (SantaCruz, Dallas, TX, USA); Clathrin and Caveolin-1 (Biosciences, San Diego, CA, USA); PTRF and integrin $\beta 4$ (Abcam, Cambridge, UK); p53 (DO7, Leica, Milton Keynes, UK); Actin (SantaCruz); phosphointegrin $\beta 4$ at Y1510 (P-integrin $\beta 4$ ) (Assay Biotechnology, Sunnyvale, CA, USA); and GM1 (Sigma).

\section{RNA interference and plasmid transfection}

Cells were transfected with siRNA duplexes and plasmids, using RNAiMAX (Invitrogen, Carlsbad, CA, USA) and Lipofectamine 2000 reagent (Invitrogen), respectively, according to the manufacturer's instructions. The following siRNAs were used:

Con $\mathrm{Si}$ (5'-CCUACGCCACCAAUUUCGUdTdT-3'),

Integrin $\beta 1 \quad \mathrm{Si}$ (5'-CAGACAUCAUUCCAAUUGUdT dT-3')

Integrin $\quad \beta 3 \quad \mathrm{Si}$ (5'-CAGAUGUCAUUCCAUAUCAd TdT-3')

Integrin $\quad \beta 4 \quad \mathrm{Si} \quad$ (5'-CUGGUAAACAUCACCAUCAd TdT- $3^{\prime}$ ),

Integrin $\beta 4 \mathrm{Si} \# 1$ (5'-GACUUCGUGUGCGGACAGUd TdT-3'),

Integrin $\beta 4 \mathrm{Si} \# 2$ (5'-ACGUCAUCAGCCUGACAGAd TdT-3'),

Integrin $\quad \beta 5 \quad \mathrm{Si} \quad\left(5^{\prime}\right.$-CUGUUGAAGGUACAUCGUUd TdT-3')

Src Si (5'- GGCUGAGGAGUGGUAUUUUdTdT-3'), and

AKT Si (5'-GACAACCGCCAUCCAGACUdTdT-3').

The plasmid expressing the pRK5 alpha6, pRK5 beta4, and pRK5 beta4 $1355 \mathrm{~T}(\Delta \mathrm{CYT})$ were a gift from Filippo Giancotti (Addgene plasmid \# 16036, \# 16037, and \#16038, respectively) [36].

\section{Isolation and characterization of lipid rafts}

A549 cells were lysed with $1 \mathrm{~mL}$ of lysis buffer (1\% Triton $\mathrm{X}-100,25 \mathrm{mM}$ HEPES, pH 6.5, $150 \mathrm{mM} \mathrm{NaCl}, 1 \mathrm{mM}$ EDTA, $1 \mathrm{mM}$ PMSF, and protease inhibitor cocktail). Equal amount of proteins was subjected to discontinuous sucrose gradient ultracentrifugation (40,30, and 5\%) using an SW41 Ti rotor $\left(39,000\right.$ r.p.m.) for $18 \mathrm{~h}$ at $4{ }^{\circ} \mathrm{C}$. After centrifugation, the sucrose gradients were fractionated into 13 fractions, including the pellet. An opaque buoyant band corresponding to the lipid rafts was collected at the interface between the 30 and 5\% sucrose gradients [28]. Aliquots of fractions collected from the bottom of the gradient were analyzed by immunoblotting. The protein concentration was determined using the bicinchoninic acid method (Thermo Fisher Scientific, Waltham, MA, USA), according to the manufacturer's protocols.

\section{Two-photon fluorescence microscopy}

Two-photon fluorescence microscopy images of SLaurdan2 (SL2)-labeled cells were obtained with spectral confocal and multiphoton microscopes (Leica TCS SP2) using a $\times 10-100$ objective, numerical aperture $(\mathrm{NA})=$ 1.30. The two-photon fluorescence microscopy images were obtained with a DM IRE2Microscope (Leica) by exciting the probes with a mode-locked titanium-sapphire laser source (Coherent Chameleon, $90 \mathrm{MHz}, 200 \mathrm{fs}$ ) set at a wavelength of $800 \mathrm{~nm}$ and output power $1488 \mathrm{~mW}$, corresponding to $\sim 10 \mathrm{~mW}$ average power in the focal plane. To obtain images at $410-530 \mathrm{~nm}$ (channel 1) range, internal PMTs were used to collect the signals in an 8 bit unsigned $512 \times 512$ pixels at $400 \mathrm{~Hz}$ scan speed [28].

\section{Phosphoprotein profiling}

The Phospho Explorer Antibody Microarray, designed and manufactured by Full Moon Biosystems Inc. (Sunnyvale, CA, USA), contains 1318 antibodies from over 30 signaling pathways. Each antibody has two replicates printed on a coated glass microscope slide, along with multiple positive and negative controls. The antibody array experiment was performed by Full Moon Biosystems, according to their established protocols [60]. The slides were scanned on an Axon GenePix array scanner, and the images were analyzed with GenePix Pro 6.0 (Molecular Devices, Sunnyvale, CA, USA). The fluorescence signal (I) of each antibody was obtained from the fluorescence intensity of its antibody spot. A ratio computation was used to measure the extent of protein phosphorylation. The phosphorylation ratio was calculated as follows: phosphorylation ratio $=$ phosphorylated value/unphosphorylated value [61].

\section{SA- $\beta$-Galactosidase staining}

Cells and tumor were stained for $\beta$-galactosidase activity, as described by Dimri et al [62]. Briefly, cells were washed in PBS and fixed for $5 \mathrm{~min}$ in $3.7 \%$ formaldehyde. Fixed cells were then incubated at $37^{\circ} \mathrm{C}$ (without $\mathrm{CO}_{2}$ ) with a fresh staining solution of $1 \mathrm{mg} / \mathrm{ml}$ 5-bromo-4-chloro-3-indolyl 
$\beta$-D-galactoside (X-Gal), prepared in a solution consisting of $40 \mathrm{mM}$ citric acid/sodium phosphate (pH 6.0), $5 \mathrm{mM}$ potassium ferrocyanide, $5 \mathrm{mM}$ potassium ferricyanide, 150 $\mathrm{mM} \mathrm{NaCl}$, and $2 \mathrm{mM} \mathrm{MgCl} 2$. Staining was evident after $12-16 \mathrm{~h}$. Cell senescence was measured using the Senescence $\beta$-Galactosidase Staining Kit for quantification of senescent cells (Enzo Life Science, Farmingdale, NY, USA).

\section{Annexin $\mathbf{V}$ and propidium iodide staining}

The apoptosis-mediated cell death was examined using an FITC-Annexin V apoptosis detection kit (BD Biosciences), as per the manufacturer's instructions. Briefly, cells were incubated with $5 \mu$ l of FITC Annexin V, followed by addition of $5 \mu \mathrm{l}$ of propidium iodide (PI) and incubation in the dark for $30 \mathrm{~min}$. The stained cells were analyzed by flow cytometric analysis (BD Biosciences).

\section{Cholesterol assay}

For staining of cholesterol in cultured cells, cells were fixed with $3 \%$ paraformaldehyde for $1 \mathrm{~h}$, washed with cold PBS, incubated with $1.5 \mathrm{mg}$ glycine/ $\mathrm{mL}$ for $10 \mathrm{~min}$ to quench the paraformaldehyde, stained with $0.05 \mathrm{mg} / \mathrm{mL}$ filipin (Sigma) for $2 \mathrm{~h}$, and more incubated with Alexa Fluor 488Phalloidin (1:1000, ThermoFisher Scientific) for $30 \mathrm{~min}$ [63]. And then washed and imaged by confocal microscopy. An Amplex red assay kit was used to measure the cholesterol content in samples according to the manufacturer's protocol (Invitrogen).

\section{Tumor-xenograft mice and in vivo experiments}

Xenograft mice were established as described previously [64]. In brief, a single-cell suspension of $\mathrm{H} 460$ cells $\left(1 \times 10^{6}\right.$ cells) was injected subcutaneously into the lateral hind leg of 6-week-old BALB/c nude mice $(\mathrm{n}=5)$. The average tumor volume was determined as $\left(\mathrm{L} \times \mathrm{W}^{2}\right) / 2$; tumor length (L) and width (W) were measured using a caliper. When the tumor reached an average volume of $\sim 100 \mathrm{~mm}^{3}$, an integrin $\beta 4$ SiRNA (Bioneer, Daejeon, Korea) mixture or PP2 (Calbiochem) with AteloGenes Local Use (KOKEN, Koraku, Tokyo) was injected to surround the whole tumor mass. After 1 day, xenografted tumors were locally exposed to IR of $12 \mathrm{~Gy}$. Local regional irradiation of xenografted tumor was performed under anesthesia; irradiation was achieved using a ${ }^{60} \mathrm{Co}$ source irradiator (Theratron 780; Atomic Energy of Canada Ltd.) operating at $1.3 \mathrm{~Gy} / \mathrm{min}$. Mice were killed for further experiments at 8 days after the IR exposure. Tumors were fixed overnight in $4 \%$ formalin, embedded in paraffin, following which they were subjected to immunohistochemistry for detection of p21 and Ki67, using the Vectastain Elite $\mathrm{ABC}$ kit (Vector Laboratories Inc., Burlingame, CA, USA), as per the manufacturer's protocol. Subsequently, the slices were counterstained by hematoxylin. Apoptosis in tumor tissue was assayed using terminal deoxynucleotidyl transferase dUTP nick end labeling (TUNEL) assay kit (Millipore), as per the manufacturer's protocol. Sections were counterstained with hematoxylin. Negative control sections were incubated with distilled water in the absence of TdT. Labeling indices for Ki67, p21, and TUNEL-positive cells were obtained from 5 randomly chosen viewing fields per tumor section, according to standard procedures. All animal studies were conducted in accordance with the guidelines of the Institutional Animal Care and Use Committee of the Korea Institute of Radiological and Medical Sciences (Approval No. KIRAMS 2016-0064).

\section{Statistical analysis}

One-way ANOVA or $t$ tests, with statistical significance $P$ $<0.05$, were performed. The data are presented as mean \pm $\mathrm{SD}$ or mean $\pm \mathrm{SEM}$.

Acknowledgements This work was supported by a grant awarded to JSL from the Medical Research Center (MRC) (2014R1A5A20 09392), Nuclear Research and Development Program (2017M2A2A7 A01070591), and the Basic Science Research Program (2017R1A2 B2007542) through the National Research Foundation (NRF) funded by the Korean government (MSIT).

\section{Compliance with Ethical Standards}

Conflict of Interest The authors declare that they have no conflict of interest.

\section{References}

1. Sharma RA, Plummer R, Stock JK, Greenhalgh TA, Ataman O, Kelly $\mathrm{S}$, et al. Clinical development of new drug-radiotherapy combinations. Nat Rev Clin Oncol. 2016;13:627-42.

2. Gewirtz DA, Holt SE, Elmore LW. Accelerated senescence: an emerging role in tumor cell response to chemotherapy and radiation. Biochem Pharmacol. 2008;76:947-57.

3. Day RM, Snow AL, Panganiban RA. Radiation-induced accelerated senescence: a fate worse than death? Cell Cycle. 2014;13:2011-2.

4. Collado M, Serrano M. Senescence in tumours: evidence from mice and humans. Nat Rev Cancer. 2010;10:51-7.

5. Kim BC, Yoo HJ, Lee HC, Kang KA, Jung SH, Lee HJ, et al. Evaluation of premature senescence and senescence biomarkers in carcinoma cells and xenograft mice exposed to single or fractionated irradiation. Oncol Rep. 2014;31:2229-35.

6. Lee JJ, Kim BC, Park MJ, Lee YS, Kim YN, Lee BL, et al. PTEN status switches cell fate between premature senescence and apoptosis in glioma exposed to ionizing radiation. Cell Death Differ. 2011;18:666-77.

7. Nardella C, Clohessy JG, Alimonti A, Pandolfi PP. Prosenescence therapy for cancer treatment. Nat Rev Cancer. 2011;11:503-11. 
8. Hayflick L, Moorhead PS. The serial cultivation of human diploid cell strains. Exp Cell Res. 1961;25:585-621.

9. Collado M, Serrano M. The power and the promise of oncogeneinduced senescence markers. Nat Rev Cancer. 2006;6:472-6.

10. Lee M, Lee JS. Exploiting tumor cell senescence in anticancer therapy. BMB Rep. 2014;47:51-9.

11. Coppe JP, Desprez PY, Krtolica A, Campisi J. The senescenceassociated secretory phenotype: the dark side of tumor suppression. Annu Rev Pathol. 2010;5:99-118.

12. Rodier F, Campisi J. Four faces of cellular senescence. J Cell Biol. 2011;192:547-56.

13. Munoz-Espin D, Canamero M, Maraver A, Gomez-Lopez G, Contreras J, Murillo-Cuesta S, et al. Programmed cell senescence during mammalian embryonic development. Cell. 2013;155:1104-18.

14. Campisi J, d'Adda di Fagagna F. Cellular senescence: when bad things happen to good cells. Nat Rev Mol Cell Biol. 2007;8:729-40.

15. Sabin RJ, Anderson RM. Cellular Senescence - its role in cancer and the response to ionizing radiation. Genome Integr. 2011;2:7.

16. Galbiati F, Razani B, Lisanti MP. Emerging themes in lipid rafts and caveolae. Cell. 2001;106:403-11.

17. Ikonen E. Roles of lipid rafts in membrane transport. Curr Opin Cell Biol. 2001;13:470-7.

18. ffrench-Constant $\mathrm{C}$, Colognato $\mathrm{H}$. Integrins: versatile integrators of extracellular signals. Trends Cell Biol. 2004;14:678-86.

19. Hynes RO. Integrins: bidirectional, allosteric signaling machines. Cell. 2002;110:673-87.

20. Giancotti FG, Ruoslahti E. Integrin signaling. Science. 1999;285:1028-32.

21. Takada Y, Ye X, Simon S. The integrins. Genome Biol. 2007;8:215.

22. Anthis NJ, Haling JR, Oxley CL, Memo M, Wegener KL, Lim CJ, et al. Beta integrin tyrosine phosphorylation is a conserved mechanism for regulating talin-induced integrin activation. J Biol Chem. 2009;284:36700-10.

23. Linge A, Meleady P, Henry M, Clynes M, Kasper M, Barth K. Bleomycin treatment of A549 human lung cancer cells results in association of MGr1-Ag and caveolin-1 in lipid rafts. Int J Biochem Cell Biol. 2011;43:98-105.

24. Gajate C, Mollinedo F. Cytoskeleton-mediated death receptor and ligand concentration in lipid rafts forms apoptosispromoting clusters in cancer chemotherapy. J Biol Chem. 2005;280:11641-7.

25. Byun HO, Han NK, Lee HJ, Kim KB, Ko YG, Yoon G, et al. Cathepsin D and eukaryotic translation elongation factor 1 as promising markers of cellular senescence. Cancer Res. 2009;69:4638-47.

26. Lee JJ, Lee JH, Ko YG, Hong SI, Lee JS. Prevention of premature senescence requires JNK regulation of Bcl-2 and reactive oxygen species. Oncogene. 2010;29:561-75.

27. Jury EC, Kabouridis PS, Flores-Borja F, Mageed RA, Isenberg DA. Altered lipid raft-associated signaling and ganglioside expression in $\mathrm{T}$ lymphocytes from patients with systemic lupus erythematosus. J Clin Invest. 2004;113:1176-87.

28. Yi JS, Mun DG, Lee H, Park JS, Lee JW, Lee JS, et al. PTRF/ cavin-1 is essential for multidrug resistance in cancer cells. J Proteome Res. 2013;12:605-14.

29. Lim CS, Kim HJ, Lee JH, Tian YS, Kim CH, Kim HM, et al. A two-photon turn-on probe for lipid rafts with minimum internalization. Chembiochem: a Eur J Chem Biol. 2011;12:392-5.

30. Zhuang L, Kim J, Adam RM, Solomon KR, Freeman MR. Cholesterol targeting alters lipid raft composition and cell survival in prostate cancer cells and xenografts. J Clin Invest. 2005;115:959-68.

31. Abbas T, Dutta A. p21 in cancer: intricate networks and multiple activities. Nat Rev Cancer. 2009;9:400-14.
32. Mercurio AM, Rabinovitz I. Towards a mechanistic understanding of tumor invasion--lessons from the alpha6beta 4 integrin. Semin Cancer Biol. 2001;11:129-41.

33. Arthur JR, Heinecke KA, Seyfried TN. Filipin recognizes both GM1 and cholesterol in GM1 gangliosidosis mouse brain. J Lipid Res. 2011;52:1345-51.

34. Chen YH, Chang SH, Wang IJ, Young TH. The mechanism for keratinocyte detaching from $\mathrm{pH}$-responsive chitosan. Biomaterials. 2014;35:9247-54.

35. Zhou X, Matskova L, Rathje LS, Xiao X, Gish G, Werner M, et al. SYK interaction with ITGbeta4 suppressed by Epstein-Barr virus LMP2A modulates migration and invasion of nasopharyngeal carcinoma cells. Oncogene. 2015;34: 4491-9.

36. Dans M, Gagnoux-Palacios L, Blaikie P, Klein S, Mariotti A, Giancotti FG. Tyrosine phosphorylation of the beta 4 integrin cytoplasmic domain mediates Shc signaling to extracellular signal-regulated kinase and antagonizes formation of hemidesmosomes. J Biol Chem. 2001;276:1494-502.

37. Chiarugi P. Src redox regulation: there is more than meets the eye. Mol Cells. 2008;26:329-37.

38. Hou J, Cui A, Song P, Hua H, Luo T, Jiang Y. Reactive oxygen species-mediated activation of the Src-epidermal growth factor receptor-Akt signaling cascade prevents bortezomib-induced apoptosis in hepatocellular carcinoma cells. Mol Med Rep. 2015;11:712-8.

39. Gervais JL, Seth P, Zhang H. Cleavage of CDK inhibitorp21 (Cip1/Waf1) by caspases is an early event during DNA damageinduced apoptosis. J Biol Chem. 1998;273:19207-12.

40. Fischer U, Janicke RU, Schulze-Osthoff K. Many cuts to ruin: a comprehensive update of caspase substrates. Cell Death Differ. 2003;10:76-100.

41. Goldkorn T, Balaban N, Shannon M, Matsukuma K. EGF receptor phosphorylation is affected by ionizing radiation. Biochim Biophys Acta. 1997;1358:289-99.

42. Zingg D, Riesterer O, Fabbro D, Glanzmann C, Bodis S, Pruschy M. Differential activation of the phosphatidylinositol 3'-kinase/Akt survival pathway by ionizing radiation in tumor and primary endothelial cells. Cancer Res. 2004;64: 5398-406.

43. Knebel A, Bohmer FD, Herrlich P. Radiation-induced signal transduction. Methods Enzymol. 2000;319:255-72.

44. Knebel A, Rahmsdorf HJ, Ullrich A, Herrlich P. Dephosphorylation of receptor tyrosine kinases as target of regulation by radiation, oxidants or alkylating agents. EMBO J. 1996;15:5314-25.

45. Rebbaa A, Zheng X, Chou PM, Mirkin BL. Caspase inhibition switches doxorubicin-induced apoptosis to senescence. Oncogene. 2003;22:2805-11.

46. Datta SR, Brunet A, Greenberg ME. Cellular survival: a play in three Akts. Genes Dev. 1999;13:2905-27.

47. Kastenhuber ER, Lowe SW. Putting p53 in context. Cell. 2017;170:1062-78.

48. Fu Y, Hou Y, Fu C, Gu M, Li C, Kong W, et al. A novel mechanism of gamma/delta T-lymphocyte and endothelial activation by shear stress: the role of ecto-ATP synthase beta chain. Circ Res. 2011;108:410-7.

49. Tavolari S, Munarini A, Storci G, Laufer S, Chieco P, Guarnieri $\mathrm{T}$. The decrease of cell membrane fluidity by the non-steroidal anti-inflammatory drug Licofelone inhibits epidermal growth factor receptor signalling and triggers apoptosis in HCA-7 colon cancer cells. Cancer Lett. 2012;321:187-94.

50. Sun X, Fu Y, Gu M, Zhang L, Li D, Li H, et al. Activation of integrin alpha5 mediated by flow requires its translocation to membrane lipid rafts in vascular endothelial cells. Proc Natl Acad Sci USA. 2016;113:769-74. 
51. Oxley CL, Anthis NJ, Lowe ED, Vakonakis I, Campbell ID, Wegener KL. An integrin phosphorylation switch: the effect of beta3 integrin tail phosphorylation on Dok1 and talin binding. $\mathbf{J}$ Biol Chem. 2008;283:5420-6.

52. Eke I, Deuse Y, Hehlgans S, Gurtner K, Krause M, Baumann M, et al. beta(1)Integrin/FAK/cortactin signaling is essential for human head and neck cancer resistance to radiotherapy. J Clin Invest. 2012;122:1529-40.

53. Ramirez NE, Zhang Z, Madamanchi A, Boyd KL, O'Rear LD, Nashabi A, et al. The alpha(2)beta(1) integrin is a metastasis suppressor in mouse models and human cancer. J Clin Invest. 2011;121:226-37.

54. Rapisarda V, Borghesan M, Miguela V, Encheva V, Snijders AP, Lujambio A, et al. Integrin beta 3 regulates cellular senescence by activating the TGF-beta pathway. Cell Rep. 2017;18:2480-93.

55. Giancotti FG, Tarone G. Positional control of cell fate through joint integrin/receptor protein kinase signaling. Annu Rev Cell Dev Biol. 2003;19:173-206.

56. Gagnoux-Palacios L, Dans M, van't Hof W, Mariotti A, Pepe A, Meneguzzi G. et al. Compartmentalization of integrin alpha6beta4 signaling in lipid rafts. J Cell Biol. 2003;162:1189-96.

57. Stewart RL, O'Connor KL. Clinical significance of the integrin alpha6beta4 in human malignancies. Lab Invest. 2015;95:976-86.
58. Raymond K, Kreft M, Song JY, Janssen H, Sonnenberg A. Dual Role of alpha6beta4 integrin in epidermal tumor growth: tumorsuppressive versus tumor-promoting function. Mol Biol Cell. 2007;18:4210-21.

59. Giancotti FG. Targeting integrin beta4 for cancer and antiangiogenic therapy. Trends Pharmacol Sci. 2007;28:506-11.

60. Bernier M, Paul RK, Martin-Montalvo A, Scheibye-Knudsen M, Song $\mathrm{S}, \mathrm{He} \mathrm{HJ}$, et al. Negative regulation of STAT3 proteinmediated cellular respiration by SIRT1 protein. J Biol Chem. 2011;286:19270-9.

61. Bosma M, Gerling M, Pasto J, Georgiadi A, Graham E, Shilkova $\mathrm{O}$, et al. FNDC4 acts as an anti-inflammatory factor on macrophages and improves colitis in mice. Nat Commun. 2016;7:11314.

62. Dimri GP, Lee X, Basile G, Acosta M, Scott G, Roskelley C, et al. A biomarker that identifies senescent human cells in culture and in aging skin in vivo. Proc Natl Acad Sci USA. 1995;92:9363-7.

63. Rai A, Pathak D, Thakur S, Singh S, Dubey AK, Mallik R. Dynein Clusters into Lipid Microdomains on Phagosomes to Drive Rapid Transport toward Lysosomes. Cell. 2016;164:722-34.

64. Jung SH, Lee HC, Yu DM, Kim BC, Park SM, Lee YS, et al. Heparan sulfation is essential for the prevention of cellular senescence. Cell Death Differ. 2016;23:417-29. 